\title{
Coronary artery calcification and vascular function
}

\author{
Sharmila Dorbala, MD, MPH, FACC, ${ }^{a, b, c}$ and Venkatesh L. Murthy, MD, PhD ${ }^{a, b}$
}

See related article, pp. 256-264

Danad et al's work reported in this issue adds to the growing evidence questioning the strength and the nature of the relationship between the anatomic magnitude of coronary atherosclerosis and its functional consequences on myocardial perfusion. The FAME trial demonstrated that for patients with overt coronary stenosis, a functional flow-guided approach leads to better outcomes than one based on anatomic measurements of stenosis severity. ${ }^{1}$ At the opposite end of the spectrum of coronary atherosclerosis, the work of Danad et $\mathrm{al}^{2}$ explores the relationship between calcified coronary atherosclerosis and perfusion among patients without overt coronary stenosis.

Confirming work previously reported using other methods, ${ }^{3-6}$ this article demonstrates that, among 173 patients referred for combined ${ }^{15} \mathrm{O}$-water PET and coronary artery computed tomography, there is a statistically significant inverse correlation between the degree of coronary artery calcification (CAC) and the myocardial blood flow (MBF) or the coronary flow reserve (CFR). However, as in prior studies, the magnitude of the correlation is modest. Furthermore, the observed association completely disappeared after correction for traditional clinical risk factors, suggesting that the observed association between myocardial perfusion and coronary artery calcification is largely due to overlapping clinical risk factors.

The lack of an observed independent relation between $\mathrm{MBF}$ and $\mathrm{CAC}$ suggests that no discernible

From the Division of Cardiovascular Imaging, Department of Radiology, Division of Cardiovascular Diseases, Department of Medicine, ${ }^{b}$ Division of Nuclear Medicine, Department of Radiology, ${ }^{\mathrm{c}}$ Brigham and Women's Hospital, Boston, MA.

Reprint requests: Sharmila Dorbala, MD, MPH, FACC, Division of Nuclear Medicine, Department of Radiology, Brigham and Women's Hospital, 75 Francis Street, ASB1, L-1, Boston, MA 02115; sdorbala@partners.org.

J Nucl Cardiol 2012;19:227-9.

1071-3581/\$34.00

Copyright (C) 2012 American Society of Nuclear Cardiology.

doi: $10.1007 / \mathrm{s} 12350-011-9503-8$ relation exists or that the effect size of the relation is too small to be detected by the given sample size and technique used. The current study used ${ }^{15} \mathrm{O}$-labeled water, the optimal radiotracer for measuring myocardial blood flow. The authors also studied longitudinal apex to base gradient, a measure of the hemodynamic effects of diffuse coronary atherosclerosis. Importantly, prior studies did not rigorously exclude the presence of epicardial coronary stenosis, relying on normal relative perfusion imaging to identify subjects unlikely to have obstructive epicardial coronary lesions. Despite these efforts, it is possible that these prior studies enrolled patients who had obstructive epicardial stenoses which would result in abnormal calcium scores and quantitative myocardial perfusion.

In contrast, Danad et al rigorously excluded obstructive lesions using either invasive or CT coronary angiography. By doing so, this study is able to explore the effects of coronary calcification on the combined hemodynamic effects of impaired vasodilator function in both non-obstructive epicardial coronary arteries and microvascular dysfunction. Additional studies would be required to separate contributions of these two components of circulatory dysfunction. Indeed, one potential reason for the lack of association in the study by Danad et al that some of the patients with abnormal CFR had exclusively microvascular dysfunction with truly normal epicardial arteries lacking calcifications. The frequency of this pattern is unfortunately not specified in their work. The use of rigorous, gold-standard methodologies, and concordance with prior studies suggests that the primary finding of this study, i.e., the lack of an independent relationship between CAC and CFR, is likely to be true.

Although the technical methods of this article are laudable, it should be kept in mind that only 29 of the 173 subjects had a CAC of $\geq 100$. Also, as the authors acknowledge, the study cohort was too small for subgroup analysis based on CAC categories. Nonetheless, the distribution of $\mathrm{CAC}$ in this study likely reflects clinical reality in symptomatic patients without obstructive CAD. Further, the study does not explore the frequency of abnormal MBF among patients with low or zero CAC. These patients would not generally be treated with $\mathrm{CAD}$ risk reduction therapies based on CAC but might be considered for prevention medications on the 
basis of the elevated cardiac risk associated with impaired CFR. ${ }^{7}$

Given that the both CAC and CFR are both abnormal in early stage atherosclerosis in the absence of flow-limiting epicardial stenosis, it was certainly tantalizing to hypothesize that these two measures would be strongly correlated. If a high degree of correlation existed between these measures, by obtaining either, one would have most of the information contained in the other. The clinical consequence of this would be that by measuring CAC, one could avoid the need to perform PET quantification of myocardial perfusion. Conversely, quantitative measurement of myocardial perfusion would allow most of the information from CAC to be obtained, while avoiding the additional radiation exposure associated with the CAC scan. Collectively, the work of Danad et al and prior studies ${ }^{3-6}$ suggest that this is not the case and each of these measurements carry largely independent information, at least in symptomatic individuals without evidence of obstructive CAD.

There are several potential explanations for this. First, these two types of measurements are assessing different aspects of coronary atherosclerosis. Calcification is an anatomic change, which may occur at varying rates in different persons, even in the presence of plaques, in part due to conditions which alter calciumphosphate homeostasis such vitamin D deficiency. ${ }^{8}$ In contrast, impaired vasodilator function reflects physiologic changes in vascular smooth muscle and endothelial function. Invasive studies have demonstrated that plaque vascular function is not well predicted by degree of anatomic stenosis alone. ${ }^{9}$ Furthermore, atheroma calcification and impaired vasodilator function may occur at different stages during the natural history of atherosclerotic lesions. Specifically, calcification is believed to occur relatively late in the natural history of atherosclerotic lesions, ${ }^{10,11}$ whereas impairment of vasodilator response is seen in even very early stage lesions. ${ }^{12}$

That CAC and the CFR reflect different aspects of atherosclerosis highlights that although their mutual correlation is weak, they may each have important roles. Indeed, multiple large studies have established that CAC has substantial incremental prognostic value beyond clinical risk assessment among asymptomatic adults. ${ }^{13,14}$ Similarly, the additional prognostic value of CFR beyond clinical risk factors and traditional stress imaging findings has been established in a large cohort of largely symptomatic patients. ${ }^{7}$ In contrast, although CAC may have incremental prognostic value beyond relative perfusion imaging findings, ${ }^{15}$ it is now recognized that even among patients with low or zero CAC a significant proportion of symptomatic patients may have obstructive CAD on angiography. ${ }^{16-19}$ As a result, symptomatic individuals may be more likely to benefit from CFR assessment rather than CAC. However, at present, no published studies have validated the incremental prognostic value or diagnostic value of CAC for detection of obstructive $\mathrm{CAD}$ beyond quantitative assessments of myocardial perfusion. Thus, whether $\mathrm{CAC}$ and quantitative myocardial perfusion assessment carry additive prognostic or diagnostic value remains an open question at present.

\section{References}

1. Tonino PAL, De Bruyne B, Pijls NHJ, Siebert U, Ikeno F, van't Veer $\mathrm{M}$, et al. Fractional flow reserve versus angiography for guiding percutaneous coronary intervention. $\mathrm{N}$ Engl $\mathrm{J}$ Med 2009;360:213-24.

2. Danad I, Raijmakers PG, Appelman YE, Harms HJ, Haan S, Marques KM, et al. Quantitative relationship between coronary artery calcium score and hyperemic myocardial blood flow as assessed by hybrid 15O-water PET/CT imaging in patients evaluated for coronary artery disease. J Nucl Cardiol 2011. http://www. springerlink.com/content/85284722ht713680. November 11, cited 2011 December 3.

3. Curillova Z, Yaman BF, Dorbala S, Kwong RY, Sitek A, Fakhri $\mathrm{G}$, et al. Quantitative relationship between coronary calcium content and coronary flow reserve as assessed by integrated PET/ CT imaging. Eur J Nucl Med Mol Imaging 2009;36:1603-10.

4. Wang L, Jerosch-Herold M, Jacobs DR Jr, Shahar E, Detrano R, Folsom AR. Coronary artery calcification and myocardial perfusion in asymptomatic adults: The MESA (Multi-Ethnic Study of Atherosclerosis). J Am Coll Cardiol 2006;48:1018-26.

5. Pirich C, Leber A, Knez A, Bengel FM, Nekolla SG, Haberl R, et al. Relation of coronary vasoreactivity and coronary calcification in asymptomatic subjects with a family history of premature coronary artery disease. Eur J Nucl Med Mol Imaging 2004;31: 663-70.

6. Schindler TH, Facta AD, Prior JO, Cadenas J, Zhang X-L, Li Y, et al. Structural alterations of the coronary arterial wall are associated with myocardial flow heterogeneity in type 2 diabetes mellitus. Eur J Nucl Med Mol Imaging 2009;36:219-29.

7. Murthy VL, Naya M, Foster CR, Hainer J, Gaber M, Di Carli G, et al. Improved cardiac risk assessment with noninvasive measures of coronary flow reserve. Circulation 2011;124:2215-24.

8. de Boer IH, Kestenbaum B, Shoben AB, Michos ED, Sarnak MJ, Siscovick DS. 25-Hydroxyvitamin D levels inversely associate with risk for developing coronary artery calcification. J Am Soc Nephrol 2009;20:1805-12.

9. Tonino PAL, Fearon WF, De Bruyne B, Oldroyd KG, Leesar MA, Ver Lee PN, et al. Angiographic versus functional severity of coronary artery stenoses in the FAME study: Fractional flow reserve versus angiography in multivessel evaluation. J Am Coll Cardiol 2010;55:2816-21.

10. Motoyama S, Kondo T, Sarai M, Sugiura A, Harigaya H, Sato T, et al. Multislice computed tomographic characteristics of coronary lesions in acute coronary syndromes. J Am Coll Cardiol 2007; 50(4):319-26

11. Naghavi M, Libby P, Falk E, Casscells SW, Litovsky S, Rumberger $\mathrm{J}$, et al. From vulnerable plaque to vulnerable patient. Circulation 2003;108:1664-72.

12. McLenachan JM, Williams JK, Fish RD, Ganz P, Selwyn AP. Loss of flow-mediated endothelium-dependent dilation occurs early in the development of atherosclerosis. Circulation 1991;84:1273-8. 
13. Elias-Smale SE, Proença RV, Koller MT, Kavousi M, van Rooij FJA, Hunink MG, et al. Coronary calcium score improves classification of coronary heart disease risk in the elderly: The Rotterdam study. J Am Coll Cardiol 2010;56:1407-14.

14. Polonsky TS, McClelland RL, Jorgensen NW, Bild DE, Burke GL, Guerci AD, et al. Coronary artery calcium score and risk classification for coronary heart disease prediction. JAMA 2010;303: 1610-6.

15. Schenker MP, Dorbala S, Hong ECT, Rybicki FJ, Hachamovitch $\mathrm{R}$, Kwong RY, et al. Interrelation of coronary calcification, myocardial ischemia, and outcomes in patients with intermediate likelihood of coronary artery disease. Circulation 2008;117:1693700 .

16. Gottlieb I, Miller JM, Arbab-Zadeh A, Dewey M, Clouse ME, Sara L, et al. The absence of coronary calcification does not exclude obstructive coronary artery disease or the need for revascularization in patients referred for conventional coronary angiography. J Am Coll Cardiol 2010;55:627-34.

17. Alqarqaz M, Zaidan M, Al-Mallah MH. Prevalence and predictors of atherosclerosis in symptomatic patients with zero calcium score. Acad Radiol 2011;18:1437-41.

18. Haberl R, Tittus J, Böhme E, Czernik A, Richartz BM, Buck J, et al. Multislice spiral computed tomographic angiography of coronary arteries in patients with suspected coronary artery disease: An effective filter before catheter angiography? Am Heart J 2005;149:1112-9.

19. Henneman MM, Schuijf JD, Pundziute G, van Werkhoven JM, van der Wall EE, Jukema JW, et al. Noninvasive evaluation with multislice computed tomography in suspected acute coronary syndrome: Plaque morphology on multislice computed tomography versus coronary calcium score. J Am Coll Cardiol 2008;52: 216-22. 